\title{
A call for international soil experiment networks for studying, predicting, and managing global change impacts
}

\author{
M. S. Torn ${ }^{1}$, A. Chabbi ${ }^{2,7}$, P. Crill ${ }^{3}$, P. J. Hanson ${ }^{4}$, I. A. Janssens ${ }^{5}$, Y. Luo ${ }^{6}$, C. H. Pries ${ }^{1}$, C. Rumpel ${ }^{7}$, \\ M. W. I. Schmidt ${ }^{8}$, J. Six ${ }^{9}$, M. Schrumpf ${ }^{10}$, and B. Zhu ${ }^{1,11}$ \\ ${ }^{1}$ Earth Sciences Division, Berkeley Lab, and UC Berkeley, Berkeley, CA 94720, USA \\ ${ }^{2}$ INRA URP3F, 86600 Lusignan, France \\ ${ }^{3}$ Department of Geological Sciences, Stockholm University, 10691 Stockholm, Sweden \\ ${ }^{4}$ Oak Ridge National Laboratory, Oak Ridge, TN 37831, USA \\ ${ }^{5}$ Biology Department, University of Antwerp, Belgium, Universiteitsplein 1, 2610 Wilrijk, Belgium \\ ${ }^{6}$ Department of Microbiology and Plant Biology, University of Oklahoma, Norman, OK 73019, USA \\ ${ }^{7}$ CNRS, IEES (UMR 7618 CNRS, UPMC, UPEC, IRD, INRA), Campus AgroParisTech, \\ 12 Thiverval-Grignon, France \\ ${ }^{8}$ Department of Geography, University of Zurich, Winterthurerstrasse 190, 8057 Zurich, Switzerland \\ ${ }^{9}$ Department of Environmental Systems Science, Swiss Federal Institute of Technology, \\ ETH Zurich, 8092 Zurich, Switzerland \\ ${ }^{10}$ Max Planck Institute for Biogeochemistry, Hans-Knöll-Straße 10, 07745 Jena, Germany \\ ${ }^{11}$ College of Urban and Environmental Sciences, and Key Laboratory for Earth Surface Processes of the \\ Ministry of Education, Peking University, Beijing 100871, China
}

Correspondence to: M. S. Torn (mstorn@lbl.gov)

Received: 4 December 2014 - Published in SOIL Discuss.: 17 February 2015

Revised: 15 June 2015 - Accepted: 2 July 2015 - Published: 24 August 2015

\section{Introduction}

The soil profile encompasses a remarkably large range of biogeochemical conditions, processes, and fluxes. For example, in most soils the turnover time of soil organic carbon (SOC) varies more between the soil surface and $1 \mathrm{~m}$ deep than between surface soils in the tropics vs. the Arctic (Torn et al., 2009). Radiocarbon observations in different soil types show that SOC decomposition rates decrease with depth, with residence times of years to decades at the soil surface to over 10000 years at $1 \mathrm{~m}$ deep (e.g., Torn et al., 2002). There are many competing hypotheses for this steep decline in SOC turnover with depth. They can be grouped loosely into physical-chemical accessibility, energetic limits to microbial activity, microclimate and $\mathrm{pH}$, and physical disconnect between decomposers and substrate. While all of these mechanisms control deep SOC cycling, data are lacking for unraveling their relative importance in different soils under different environmental conditions. This is, however, critical knowledge for predicting soil responses to global change, because fairly rapid loss (or gain) of old and/or deep SOC stocks is possible and more than $80 \%$ of the world's SOC is found below $20 \mathrm{~cm}$ depth (Jobbágy and Jackson, 2000). Currently, the soil modules within Earth system models are parameterized for surface soil and lack mechanisms important for stabilization and losses of deep SOC. Hence, we suggest that a critical challenge is to achieve process-level understanding at the global level and the ability to predict whether, and how, the large stores of deep, old SOC are stabilized and lost under global change scenarios.

As historical pressures and dependence on soils for food and fuel production continue, the coming century brings new, global changes as well. Two of the most widespread impacts of anthropogenic activities on soils in this century will be warmer temperatures (Fig. 1) and altered plant allocation belowground due to elevated atmospheric $\mathrm{CO}_{2}$ concentra- 


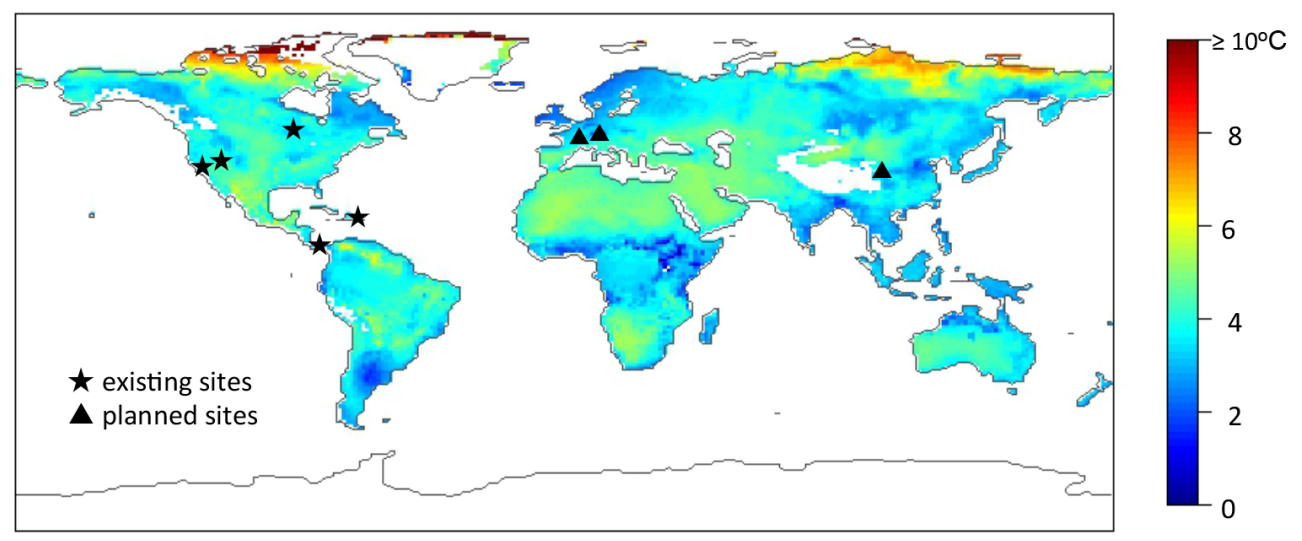

Figure 1. Predicted soil warming and the locations of existing and planned sites in the International Soil Experiment Network (iSEN). Warming is the mean 2080-2100 temperature relative to a 1986-2005 baseline, at $0.01 \mathrm{~m}$ soil depth, based on CESM RCP 8.5 (Meehl et al., 2012; map of soil warming from C. Phillips, personal communication, 2014). The symbols indicate sites that are operational, under construction, or in the planning phase in the International Soil Experiment Network. Any team that is prepared to follow the network principles is invited to join the network. Existing sites (three are operational, two are under construction): (1) U.S. SPRUCE (boreal peatland, Histosol) (see Fig. 2), (2) U.S. Hopland (annual grassland, Mollisol), (3) U.S. Blodgett (coniferous forest, Alfisol), (4) Puerto Rico (tropical forest, Ultisol), (5) Panama (tropical forest, soil order has not been determined). Planned sites: (1) Switzerland Lägeren (temperate broadleaf forest, Cambisol). (2) France Lusignan (grassland and cropland, Cambisol). (3) China Haibei (alpine grassland, Cambisol).

tions (Luo et al., 2006) and deposition of reactive nitrogen (Janssens et al., 2010). The resulting effects on SOC cycling are less certain: warming may increase microbial activity and therefore accelerate SOC turnover (Davidson and Janssens 2006; Conant et al., 2011), while more plant allocation belowground may increase stocks due to additional inputs or decrease stocks through priming effects (Kuzyakov, 2010; Cheng et al., 2014). Climate-change impacts will be compounded with growing levels of nitrogen deposition, ozone pollution, and land use and land cover change. Societal reliance on soil ecosystem services, and the threat of large positive climate feedbacks, demands that we understand surface and deep soil responses to global change and how to enhance the resilience of soil systems across the whole soil profile.

\section{The need for deep soil manipulation experiments}

To achieve generalizable understanding of soil response to global change, and to test management solutions in realworld conditions, we need controlled experiments that are carried out in situ, consider the whole soil profile, and are at locations spanning a range of conditions. Field manipulation experiments fill a critical niche as complements to natural gradient studies and laboratory incubations. While laboratory studies have been useful for exploring relative responses to different factors, such as temperature, moisture, and nutrients (e.g., Fang et al., 2005; Fierer and Schimel, 2002; Reichstein et al., 2005), they have substantial artifacts - such as a lack of plants, disrupted soil structure, and fairly constant temperature and moisture - and hence cannot represent the complex interactions occurring in situ that we seek to understand.
Natural gradients can provide insights into the influence of different environmental factors on soil biogeochemistry, but they have their own limitations for global change research. For example, most spatial climate gradients are in quasi-steady state, whereas global change impacts are largely a question of transient responses (conversely, experimental manipulations by themselves are often too short to reveal long-term responses; Luo et al. 2011). Often, factors of interest co-vary, making it difficult to isolate mechanisms or quantify response functions. For example, seasonally warmer temperatures often co-vary with plant leaf area and root exudation, and heat waves often coincide with drought (Williams et al. 2014).

Field manipulation experiments overcome many of the limitations of laboratory and gradient studies. Controlled manipulations allow key variables to be held relatively constant while others are changed, providing methods to test cause and effect and isolate direct response functions within real ecosystems. Moreover, anthropogenic activity is creating unprecedented conditions, such as hyper-tropical temperatures (Meehl et al., 2012), that cannot be found in natural gradients. While manipulations involve significant infrastructure and costs, and have artifacts and limitations, they represent an essential approach for understanding soil dynamics (Hanson et al., 2008).

\section{Opportunities for forming a global soil experiment network}

Networks of replicated experiments are essential to reveal broad-scale mechanisms underlying ecosystem responses to 


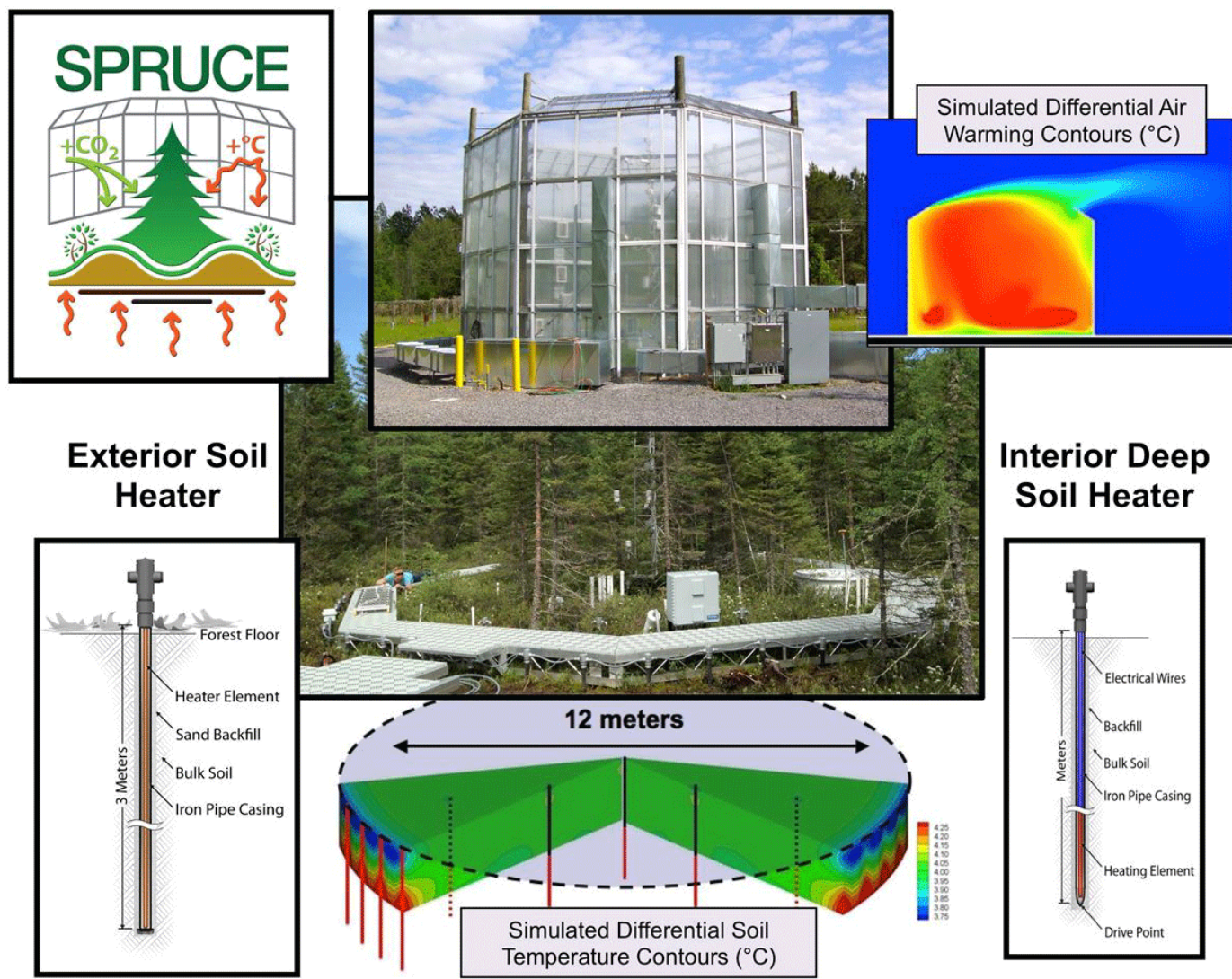

Figure 2. The experiment on Spruce and Peatland Responses Under Climatic and Environmental Change (SPRUCE) exposes a boreal forest to whole-ecosystem warming combined with elevated $\mathrm{CO}_{2}$ (http://mnspruce.ornl.gov). The warmed air space above active deep-soil warming maintains temperature differentials from ambient conditions while retaining annual, seasonal, and diurnal variations. Enclosure walls makes warming the vertical air space relatively affordable.

global change because the response of SOC cycling to global change factors depends on environmental conditions that vary spatially as well as with soil depth (e.g., Sanaullah et al., 2012; Gillabel et al., 2010; Plante et al., 2009; Mellilo et al., 2011). These controls are not well understood, making it difficult to extrapolate results from isolated experiments (Janssens et al., 2010; Davidson and Janssens, 2006). Moreover, long-term soil warming experiments, for example, show transient increases and decreases in soil respiration and SOC stocks over time, attributed to SOC depletion, changes in plant input chemistry, and microbial acclimation (e.g., Hartley et al., 2007; Bradford et al., 2008; Saleska et al., 2002; Frey et al., 2013). In general, it is difficult to extrapolate results from one experiment to other locations, and from short- to long-term responses, without much greater understanding of how ecosystem properties shape the responses.

Soil experiments have been conducted in various ecosystems, and some have been coordinated in networks (Table 1). Nevertheless, meta-analyses of the environmental factors influencing the response of SOC storage and turnover have been hampered by differences in treatments. For example, sites differ in the soil depths manipulated, magnitude of ma- nipulation (even with consistent design, the magnitude of manipulation can be site-dependent), manipulation duration, co-variables manipulated, and measurements made (Bai et al., 2013; Rustad et al. 2001). Thus, enhanced support for coordination at the initiation of experiments would be beneficial.

There is a need to integrate experiments in different places to achieve more global coverage for the study of soil responses to global change, such as warming and altered precipitation, extreme climate events, elevated tropospheric ozone concentration, and deposition (Paustian et al., 1995). The integration of manipulation studies would create new research opportunities to study whole-soil responses - opportunities that would be amplified by effective exchange of data and expertise. Moreover, the implementation of a network of coordinated experimental facilities would allow the productive sharing of knowledge and skills in service of maintaining complex experiments.

Hence, global change research calls for an international network of coordinated ecosystem experiments representing the most important soil regions of the world, spanning a range of soil types, climate, and vegetation zones (Fraser et 
Table 1. Soil experiment networks. These are some of the existing soil experiment networks. Most manipulate the litter layer and topsoil, except the iSEN which is focused on the whole soil profile.

\begin{tabular}{|c|c|c|c|}
\hline Network & Description & Years active & Reference, URL \\
\hline LIDET & $\begin{array}{l}\text { Long-term Inter-site Decomposition Experiment Team: } \\
\text { effect of substrate quality and macroclimate on litter } \\
\text { decomposition and nutrient dynamics }\end{array}$ & $1990-2000$ & $\begin{array}{l}\text { Parton et al. (2007) } \\
\text { http://andrewsforest.oregonstate. } \\
\text { edu/research/intersite/lidet.htm }\end{array}$ \\
\hline DIRT & $\begin{array}{l}\text { Detritus Input and Removal Treatments: impact of rates and } \\
\text { sources of plant inputs on the accumulation and dynamics } \\
\text { of SOM and nutrients in forest soils }\end{array}$ & 1990-present & $\begin{array}{l}\text { Nadelhoffer et al. (2006) } \\
\text { http://dirt.oregonstate.edu }\end{array}$ \\
\hline ITEX & $\begin{array}{l}\text { International Tundra Experiment: impact of warming (air } \\
\text { and surface soil) on tundra ecosystems }\end{array}$ & 1992-present & $\begin{array}{l}\text { Elmendorf et al. (2012) } \\
\text { http://ibis.geog.ubc.ca/itex/ }\end{array}$ \\
\hline LTSE & $\begin{array}{l}\text { Long-Term Soil Experiments: management control over } \\
\text { soil carbon and nutrient cycling }\end{array}$ & 2004-present & $\begin{array}{l}\text { Richter et al. (2007) } \\
\text { http://nicholas.duke.edu/ltse/ }\end{array}$ \\
\hline SOERE-ACBB & $\begin{array}{l}\text { Systems of Observation and Experimentation in Environ- } \\
\text { mental Research in Agro-ecosystems, Biochemical cycles } \\
\text { and Biodiversity. Long-term field experiments. }\end{array}$ & 2005-present & $\begin{array}{l}\text { Klumpp et al. (2011), Senapati et al. } \\
\text { (2014) } \\
\text { http://www.soere-acbb.com/ }\end{array}$ \\
\hline NutNet & $\begin{array}{l}\text { Nutrient Network: impact of nutrients and herbivores on } \\
\text { grassland diversity and productivity }\end{array}$ & 2006-present & $\begin{array}{l}\text { Borer et al. (2014) } \\
\text { http://nutnet.umn.edu/ }\end{array}$ \\
\hline CLIMMANI & $\begin{array}{l}\text { Climate Change Manipulation Experiments in Terrestrial } \\
\text { Ecosystems: Networking and Outreach }\end{array}$ & 2008-present & www.climmani.org \\
\hline INTERFACE & $\begin{array}{l}\text { An Integrated Network for Terrestrial Ecosystem Research } \\
\text { on Feedbacks to the Atmosphere and ClimatE }\end{array}$ & 2010-present & $\begin{array}{l}\text { https://www.bio.purdue.edu/ } \\
\text { INTERFACE/ }\end{array}$ \\
\hline RhizoNet & $\begin{array}{l}\text { Linking roots, the rhizosphere and soil science with above- } \\
\text { ground ecosystem ecology: a network of sites monitoring } \\
\text { rhizosphere processes. }\end{array}$ & 2013-present & http://www.rhizonetscience.com/ \\
\hline Drought-Net & $\begin{array}{l}\text { A global network to assess terrestrial ecosystem response } \\
\text { to drought: International Drought Experiment }\end{array}$ & 2014-present & $\begin{array}{l}\text { http://wp.natsci.colostate.edu/ } \\
\text { droughtnet/ }\end{array}$ \\
\hline iSEN & $\begin{array}{l}\text { International Soil Experiment Network: deep soil warming } \\
\text { and addition of isotopically labeled litter in soil profile. }\end{array}$ & 2014-present & http://soilexperimentnetwork.org \\
\hline
\end{tabular}

al., 2013). As much as possible, these should include global change experiments arrayed along environmental or land-use gradients to disentangle effects of the various factors affecting responses in real-world ecosystems.

\section{The benefits of a global network of soil manipulation experiments}

A network of relatively standardized and integrated manipulation experiments would have benefits for multi-site synthesis activities, model development and testing, generating generalizable knowledge, and education and mentoring. Once sites are established that provide the desired commonalities and contrasts, and operating in a consistent manner, the comparability of measurements and treatments would accelerate our understanding far beyond the current state of the art. This is currently not the case in ad hoc networks. An example is found in the lack of standardization of soil moisture measurements, which was recently reported to hamper a synthesis of ecosystem drought manipulation experiments (Vicca et al., 2012). Comparability of manipulation infrastructure, treatment levels, and measurements would make samples and results readily comparable. Syntheses of more standardized experiments would enable strong tests of Earth system models, and more precise knowledge of how key processes and parameters vary globally.

Collaboration among network participants may also provide financial and intellectual bonuses. For example, if only one group could produce isotopically labeled litter or conduct a high cost or specialized analysis for the entire network, each team could focus their resources to make unique contributions. In addition, the learning experience from existing sites reduces the risks involved in starting up a new site. Science teams can take advantage of support for highlevel networking (e.g., EU COST and U.S. NSF RCN programs), transnational access (e.g., INTERACT), and shared education (e.g., GREENCYCLES and PIRE). Thus, a well- 
established network may enhance funding opportunities, through recognition, leverage, and risk sharing.

Having closely related experiments also allows students and staff trained at one site to transfer their knowledge to new staff at other experiments. This not only provides a pool of expertise that is less volatile than that of single-site experiments, but also allows easier transfer of capabilities to lessdeveloped institutions or countries. Wonderful opportunities for students arise when they have access to multiple sites and facilities because they can interact with multiple investigators and be trained by different groups within the network who excel in different aspects of the network's research. One of the most important outcomes is that the multi-disciplinary nature of the network is likely to train a new generation of students that can integrate knowledge at a much higher level than currently possible.

Well-designed networks are also invaluable to outside collaborators who give added value to the network by conducting novel measurements, testing new methods, and promoting evolution of the network to new and ever-relevant applications.

\section{Site selection for an international network of soil manipulation experiments}

Site selection is a critical step in developing a network focused on determining SOC dynamics throughout the soil profile. The history, chemical characterization, and setting (climatic, hydrological, and geological) of sites have to be considered within the framework of the questions the experiments are designed to address. Criteria must be established to define the context and the contrasts desired for experiments, for example how sites differ in soil structure, chemistry, macro elements like $\mathrm{C}, \mathrm{N}$, and $\mathrm{P}$, as well as biologically important trace elements. In addition, a set of selected soil profiles that are representative of important soil types, well characterized, and span environmental gradients should be established to serve as benchmarks.

Certain land uses or areas of the globe may be high priority, depending on the soil ecosystem services in question. Peatland and permafrost ecosystems contain large carbon stocks that are potentially very vulnerable to global change; arable land is the logical focus for food security research.

Field experiments become even more effective if they can be nested within environmental gradients (Jenny, 1941), to allow for interaction among factors, space-for-factor substitution, and analysis at different timescales of response.

Soil experiment networks could take advantage of existing observational networks and experimental facilities to find locations with good site characterization, infrastructure, and access to resources. Examples of international field networks having a range of land management and cover, longterm support, and mandates compatible with hosting global change manipulations include: the European infrastructure for analysis and experimentation on ecosystems (AnaEE www.anaee.com/); Critical Zone Observatories (see Banwart et al., 2012, for an example of nesting manipulations within a CZO network), the Long-Term Ecological Research network; and experiments listed in Table 1. Field experiments could be linked to facilities like ecotrons and lysimeters (e.g., www.ecotron.cnrs.fr/index.php/en/) for more control over precipitation inputs, soil moisture, and air temperature. We also encourage taking advantage of opportunities for whole ecosystem experiments (Fig. 2).

Manipulative experiments have fairly substantial logistical and infrastructure requirements, such as requiring line power for soil warming, that will also drive site selection. Thus, in practice, a balance will be struck between selecting sites that leverage existing facilities that create clean environmental gradients and those that are conducive for obtaining funding.

\section{Critical ingredients for network success}

Cooperation, transparency, collaboration, and support are the basic elements of a successful network. The concept of the network needs to be well defined but not prescriptive, in other words, goals should be well defined but flexible enough to respond effectively to technological advances and shifting scientific issues and questions. For networks to have their greatest impact, we recommend the following:

- Shared data: open data access with fair data use policies.

- Shared opportunities: building trust and collaboration among partners, such as early invitations to collaborate and to contribute to student advising in the network.

- Shared research: scientists working across sites from the very beginning, such as postdoctoral students supported to lay the ground work for synthesis before and as data are generated.

- Shared successes: every network team needs early success, the more-established groups can mentor lessexperienced groups.

- Shared resources and facilities: engineering designs, protocols, databases, analytical facilities, technical coordination, and protocols for meta-analyses.

Networks need multidisciplinary research teams, consisting of scientists as well as engineers, technicians, and data managers. The complex interactions among ecosystem components require the involvement of researchers from many different disciplines. Modeling is important within the network for planning, experimental design, and data management. Modeling conducted before the experiments are implemented can evaluate and improve the sensitivity of the experiments to detect ecosystem changes, including changes 
in replication and duration (Luo et al., 2011). Furthermore, model predictions can generate hypotheses to be tested by the network experiments and hence identify needed measurements. Network observations and findings should lead to improvements in model structure and parameters.

Technical support is critical to achieving the high scientific potential of an experimental network and to attend to the design, building, day-to-day operation, and maintenance of experiments. A network coordinator ensures that network projects use resources efficiently, avoid duplication of efforts yet make essential measurements, and share data and information. Funding for resources that would be shared internationally, like coordination and database management, can be difficult to sustain but is essential for long-term success.

\section{The international soil experiment network for deep soil warming}

As one example of how such a network might operate: we are establishing a new network of soil experiments called iSEN (international Soil Experiment Network; Fig. 1), guided by the question: what are the effects of global warming on whole soil profile ecosystem services? The structure of iSEN is similar to a franchised business. The network develops the framework of core measurements and manipulations, provides the "recipes" - the protocols for experimental manipulations, basic measurements, and data formats - and the structure for shared resources such as databases. The principal investigator (PI) for each site obtains their own funding and may add experimental manipulations and measurements onto the core framework. The proposed network will define a minimum standard for the protocols and treatments needed to qualify to participate in the network, while allowing individual sites to add treatments reflecting their context. A key benefit of the network is that the data will be comparable across sites, allowing for robust synthesis and meta-analysis.

Currently, the proposed core manipulations are warming and the addition of ${ }^{13} \mathrm{C}-/{ }^{15} \mathrm{~N}$-labeled litter with optional water and nitrogen manipulations. Another feature that sets this network apart from other soil experiments (or networks) is that measurements and manipulations will not be limited to only surface soil; our goal is to study responses across the entire soil profile or at least to $1 \mathrm{~m}$. The initial focus is on SOC cycling, but many teams will also examine nutrient dynamics and other questions related to ecosystem services that soils provide. As a network of independent PIs, we envision the network will evolve in membership, protocols, experimental manipulations, and priorities, shaped by new environmental problems and new opportunities.

We envision a network of global scale. Applying the same experimental setup and analytical protocols to various sites will allow for the identification of general patterns in the response of SOC storage and turnover to soil warming and definition of controlling environmental and soil variables. These response functions will facilitate the upscaling of experimental and observational results to larger spatial scales. Improvement in mechanistic understanding of soil processes will be used to improve local soil-profile and Earth system models.

\section{Conclusions}

Fluxes of soil carbon to the atmosphere occur globally but are the product of locally controlled processes, and are thus governed by different mechanisms in different ecosystems, with different histories and local conditions. No single supersite, or gradient, can give us the generalizable knowledge that global prediction requires. Instead, networks of experimental manipulations that investigate the whole soil profile, nested in natural environmental gradients, provide the most promising approach to studying global change effects on soil ecosystem services. There are numerous opportunities to leverage existing observational networks to create such gradients.

In general, networks should be based on coordinated longterm experiments, process studies within these experiments, and modeling to underpin and extrapolate results from the experiments. The resulting reduced uncertainty regarding the role of soils as positive or negative feedbacks to global change will improve future climate projections. Finally, with the knowledge gained from such a global network, sciencebased mitigation strategies and solutions for current and future ecological and agricultural challenges could be developed and tested at the network's experimental facilities. As such, soil networks like those proposed here have a unique and important role in advancing soil science for global challenges.

Acknowledgements. For initiating the international Soil Experiment Network, we acknowledge the support of the US Department of Energy, Office of Science, Office of Biological and Environmental Research Terrestrial Ecosystem Science Program under contract number DE-AC02-05CH11231. I. A. Janssens acknowledges support from the European Research Council Synergy grant 610028 (IMBALANCE-P). A. Chabbi acknowledges support from the European Commission Grant Agreement no. 312690 and ANR-11-INBS-0001.

Edited by: D. Dunkerley

\section{References}

Bai, E., Li, S. L., Xu, W. H., Li, W., Dai, W. W., and Jiang, P.: A meta-analysis of experimental warming effects on terrestrial nitrogen pools and dynamics, New Phytol., 199, 441-451, 2013.

Banwart, S., Menon, M., Bernasconi, S. M., Bloem, J., Blum, W. E. H., Maia de Souza, D., Davidsdotir, B., Duffy, C., Lair, G. J., Kram, P., Lamacova, A., Lundin, L., Nikolaidis, N. P., Novak, M., Panagos, P., Ragnarsdottir, K. V., Reynolds, B., Robinson, 
D., Rousseva, S., de Ruiter, P., van Gaans, P., Weng, L., White, T., and Zhang, B.: Soil processes and functions across an international network of Critical Zone Observatories: Introduction to experimental methods and initial results, C. R. Geoscience, 344, 758-772, 2012.

Borer, E. T., Harpole, W. S., Adler, P. B., Lind, E. M., Orrock, J. L., Seabloom, E. W., and Smith, M. D.: Finding generality in ecology: a model for globally distributed experiments, Methods Ecol. Evolut., 5, 65-73, doi:10.1111/2041-210X.12125, 2014.

Bradford, M. A., Davies, C. A., Frey, S. D., Maddox, T. R., Melillo, J. M., Mohan, J. E., Reynolds, J. F., Treseder, K. K., and Wallenstein, M. D.: Thermal adaptation of soil microbial respiration to elevated temperature, Ecol. Lett., 11, 1316-1327, 2008.

Cheng, W. X., Parton, W. J., Gonzalez-Meler, M. A., Phillips, R., Asao, S., McNickle, G. G., Brzostek, E., and Jastrow, J. D.: Tansley review - Synthesis and modeling perspectives of rhizosphere priming, New Phytol., 201, 31-44, 2014.

Conant, R. T., Ryan, M. G., Ågren, G. I., Birge, H. E., Davidson, E. A., Eliasson, P. E., Evans, S.E., Frey, S. D., Giardina, C. P., Hopkins, F. M., Hyvönen, R., Kirschbaum, M. U. F., Lavallee, J. M., Leifeld, J., Parton, W. J., Megan Steinweg, J., Wallenstein, M. D., Martin Wetterstedt, J. A., and Bradford, M. A.: Temperature and soil organic matter decomposition rates synthesis of current knowledge and a way forward, Glob. Change Biol., 17, 3392-3404, doi:10.1111/j.1365-2486.2011.02496.x, 2011.

Davidson, E. A. and Janssens, I. A.: Temperature sensitivity of soil carbon decomposition and feedbacks to climate change, Nature, 440, 165-173, 2006.

Elmendorf, S. C., Henry, G. H. R., Hollister, R. D., Björk, R. G., Bjorkman, A. D., Callaghan, T. V., Collier, L. S., Cooper, E. J., Cornelissen, J. H. C., Day, T. A., Fosaa, A. M., Gould, W. A., Grétarsdóttir, J., Harte, J., Hermanutz, L., Hik, D. S., Hofgaard, A., Jarrad, F., Jónsdóttir, I. S., Keuper, F., Klanderud, K., Klein, J. A., Koh, S., Kudo, G., Lang, S. I., Loewen, V., May, J. L., Mercado, J., Michelsen, A., Molau, U., Myers-Smith, I. H., Oberbauer, S. F., Pieper, S., Post, E., Rixen, C., Robinson, C. H., Schmidt, N. M., Shaver, G. R., Stenström, A., Tolvanen, A.,Totland, Ø., Troxler, T., Wahren, C.-H., Webber, P. J., Welker, J. M., and Wookey, P. A.: Global assessment of experimental climate warming on tundra vegetation: heterogeneity over space and time, Ecol. Lett., 15, 64-175, doi:10.1111/j.14610248.2011.01716.x, 2012.

Fang, C., Smith, P., Moncrieff, J. B., and Smith, J. U.: Similar response of labile and resistant soil organic matter pools to changes in temperature, Nature, 433, 57-59, 2005.

Fierer, N. and Schimel, J. P.: Effects of drying-rewetting frequency on soil carbon and nitrogen transformations, Soil Biol. Biochem., 34, 777-787, 2002.

Fraser, L. H., Henry, H. A. L., Carlyle, C. N., White, S. R., Beierkuhnlein, C., Cahill Jr., J. F., Casper, B. B., Cleland, E., Collins, S. L., Dukes, J. S., Knapp, A. K., Lind, E., Long, R., Luo, Y., Reich, P. B., Smith, M. D., Sternberg, M., and Turkington, R.: Coordinated distributed experiments: an emerging tool for testing global hypotheses in ecology and environmental science, Front. Ecol. Environ., 11, 147-155, doi:10.1890/110279, 2013.

Frey, S. D., Lee, J., Melillo, J. M., and Six, J.: The temperature response of soil microbial efficiency and its feedback to climate, Nat. Clim. Change, 3, 395-398, 2013.
Gillabel, J., Cebrian-Lopez, B., Six, J., and Merckx, R.: Experimental evidence for the attenuating effect of SOM protection on temperature sensitivity of SOM decomposition, Glob. Change Biol., 16, 2789-2798, 2010.

Hanson, P. J., Classen, A., Kueppers, L., Luo, Y., McDowell, N. G., Morris, J., Rogers, A., Thornton, P., Ceulemans, R., Dukes, J., Goulden, M., Jackson, R., Knapp, A., Kirschbaum, M., Lewin, K., MacCracken, M., Melillo, J., Ringler, T., and Workshop Participants: Ecosystem Experiments: Understanding Climate Change Impacts On Ecosystems and Feedbacks to the Physical Climate. Workshop Report on Exploring Science Needs for the Next Generation of Climate Change and Elevated $\mathrm{CO}_{2}$ Experiments in Terrestrial Ecosytems, 14-18 April 2008, Arlington, Virginia, USA, available at: http://science.energy.gov/ / media/ber/pdf/Ecosystem_experiments.pdf (last access: $16 \mathrm{Au}-$ gust 2015), 2008.

Hartley, I. P., Heinemeyer, A., and Ineson, P.: Effects of three years of soil warming and shading on the rate of soil respiration: substrate availability and not thermal acclimation mediates observed response, Glob. Change Biol., 13, 1761-1770, 2007.

Janssens, I. A., Dieleman, W., Luyssaert, S., Subke, J. A., Reichstein, M., Ceulemans, R., Ciais, P., Dolman, A. J., Grace, J., Matteucci, G., Papale, D., Piao, S. L., Schulze, E. D., Tang, J., and Law, B. E.: Reduction of forest soil respiration in response to nitrogen deposition, Nat. Geosci., 3, 315-322, 2010.

Jenny, H: Factors of Soil Formation, McGraw-Hill, New York, USA, 1941.

Jobbágy, E. G. and Jackson, R. B.: The vertical distribution of soil organic carbon and its relation to climate and vegetation, Ecol Appl., 10, 423-436, 2000.

Klumpp, K., Tallec, T., Guix, N., and Soussana, J. F.: Long-term impacts of agricultural practices and climatic variability on carbon storage in a permanent pasture, Glob. Change Biol., 17, 3534 3545, 2011.

Kuzyakov, Y.: Priming effects: Interactions between living and dead organic matter, Soil Biol. Biochem., 42, 1363-1371, 2010.

Luo, Y., Hui, D., and Zhang, D.: Elevated carbon dioxide stimulates net accumulations of carbon and nitrogen in terrestrial ecosystems: A meta-analysis, Ecology, 87, 53-63, 2006.

Luo, Y. Q., Melillo, J., Niu, S. L., Beier, C., Clark, J. S., Classen, A. T., Davidson, E., Dukes, J. S., Evans, R. D., Field, C. B., Czimczik, C. I., Keller, M., Kimball, B. A., Kueppers, L., Norby, R. J., Pelini, S. L., Pendall, E., Rastetter, E., Six, J., Smith, M., Tjoelker, M., and Torn, M.: Coordinated approaches to quantify long-term ecosystem dynamics in response to global change, Glob. Change Biol., 17, 843-854, 2011.

Meehl, G. A., Washington, W. M, Arblaster, J. M., Hu, A., Teng, H., Tebaldi, C., Sanderson, B. N., Lamarque, J. F., Conley, A., Strand, W. G., and White, J. B.: Climate system response to external forcings and climate change projections in CCSM4, J. Climate, 25, 3661-3683, doi:10.1175/JCLI-D-11-00240.1, 2012.

Melillo, J. M., Butler, S., Johnson, J., Mohan, J., Steudler, P., Lux, H., Burrows, E., Bowles, F., Smith, R., Scott, L., Vario, C., Hill, T., Burton, A., Zhou, Y., and Tang, J.: Soil warming, carbonnitrogen interactions, and forest carbon budgets, P. Natl. Acad. Sci., 108, 9508-9512, 2011.

Nadelhoffer, K., Aitkenhead, J., Boone, R., Bowden, R., Canary, J., Kaye, J., Lajtha, K., McDowell, W., Micks, P., and Ricca, A. The DIRT experiment, Forests in Time: The environmental con- 
sequences of 1000 years of change in new england, 300, 300315, Yale University Press, New Haven, CT, USA, 2006.

Parton, W., Silver, W. L., Burke, I. C., Grassens, L., Harmon, M. E., Currie, W. S., King, J. Y., Adair, E. C., Brandt, L. A., Hart, S. C., and Fasth, B.: Global-Scale Similarities in nitrogen release patterns during long-term decomposition, Science, 315, 361-364, doi:10.1126/science.1134853, 2007.

Paustian, K., Elliott, E. T., Collins, H. P., Cole, C. V., and Paul, E. A.: Use of a network of long-term experiments for analysis of soil carbon dynamics and global change: the North American model, Anim. Prod. Sci., 37, 929-939, 1995.

Plante, A. F., Six, J., Paul, E. A., and Conant, R. T.: Does physical protection of soil organic matter attenuate temperature sensitivity?, Soil Sci. Soc. Am. J., 73, 1168-1172, 2009.

Reichstein, M., Subke, J. A., Angeli, A. C., and Tenhunen, J. D.: Does the temperature sensitivity of decomposition of soil organic matter depend upon water content, soil horizon, or incubation time?, Glob. Change Biol., 11, 1754-1767, 2005.

Richter, D., Hofmockel, M., Callaham, M., Powlson, D., and Smith, P.: Long-term soil experiments: keys to managing earth's rapidly changing ecosystems, Soil Sci. Soc. Am. J., 71, 266-279, doi:10.2136/sssaj2006.0181, 2007.

Rustad, L. E., Campbell, J. L., Marion, G. M., Norby, R. J., Mitchell, M. J., Hartley, A. E., Cornelissen, J. H. C., Gurevitch, J., and Gcte, N.: A meta-analysis of the response of soil respiration, net nitrogen mineralization, and aboveground plant growth to experimental ecosystem warming, Oecologia, 126, 543-562, 2001.

Saleska, S. R., Shaw, M. R., Fischer, M. L., Dunne, J. A., Still, C. J., Holman, M. L., and Harte, J.: Plant community composition mediates both large transient decline and predicted long-term recovery of soil carbon under climate warming, Global Biogeochem. Cy., 16, 1055, doi:10.1029/2001GB001573, 2002.
Sanaullah, M., Chabbi, A., Rumpel, C., and Kuzyakov, Y.: Carbon allocation in grassland communities under drought stress followed by ${ }^{14} \mathrm{C}$ pulse labelling, Soil Biol. Biochem., 55, 132-139, 2012.

Senapati, N., Chabbi, A., Gastal, F., Smith, P., Mascher, N., Loubet, B., Cellier, P., and Naisse, C.: Net carbon storage measured in a mowed and grazed temperate sown grassland shows potential for carbon sequestration under grazed system, Carbon Manage., 5, 131-144, 2014.

Torn, M. S., Lapenis, A. G., Timofeev, A., Fischer, M. L., Babikov, B. V., and Harden, J. W.: Organic carbon and carbon isotopes in modern and 100-year-old-soil archives of the Russian steppe, Glob. Change Biol., 8, 941-953, doi:10.1046/j.13652486.2002.00477.x, 2002.

Torn, M. S., Swanston, C. W., Castanha, C., and Trumbore, S. E.: Storage and turnover of natural organic matter in soil, in: IUPAC Series on Biophysico-chemical Processes in Environmental Systems; Volume 2 - Biophysico-chemical processes involving natural nonliving organic matter in environmental systems, edited by: Huang, P. M. and Senesi, N., John Wiley \& Sons, Inc., Hoboken, New Jersey, USA, 2009.

Vicca, S., Luyssaert, S., Peñuelas, J., Campioli, M., Chapin, F. S., Ciais, P., Heinemeyer, A., Högberg, P., Kutsch, W. L., Law, B. E., Malhi, Y., Papale, D., Piao, S. L., Reichstein, M., Schulze, E. D., and Janssens, I. A.: Fertile forests produce biomass more efficiently, Ecol. Lett., 15, 520-526, doi:10.1111/j.14610248.2012.01775.x, 2012.

Williams, I. N., Torn, M. S., Riley, W. J., and Wehner, M. F.: Impacts of climate extremes on gross primary production under global warming, Environ. Res. Lett., 9, 094011, doi:10.1088/17489326/9/9/094011, 2014. 